УДК 372.82

DOI 10.23951/2307-6127-2020-2-52-59

\title{
ЭКСКУРСИОННАЯ РАБОТА В ПРЕПОДАВАНИИ РЕЛИГИОВЕДЧЕСКИХ ДИСЦИПЛИН: ОПЫТ ТОМСКОГО ГОСУДАРСТВЕННОГО ПЕДАГОГИЧЕСКОГО УНИВЕРСИТЕТА
}

\author{
Н. И. Сазонова, О. А. Райкова
}

Томский государственный педагогический университет, Томск

Анализируется опыт Томского государственного педагогического университета по проведению экскурсий на религиоведческую тематику. Обосновывается необходимость экскурсий в культовые сооржения различных конфессий в рамках религиоведческих дисциплин, представляется опыт презентации религий через подобные мероприятия. Рассматриваются специфика аудитории экскурсии, особенности реакции на религиозную культуру, характер полученных знаний, их влияние на формирование профессионального педагога. На основе опыта проведения экскурсий анализируются изменения в восприятии религиозной культуры, которые происходят у слушателей.

Ключевые слова: экскурсия, религия, феноменологический подход, религиозная конфессия, религиозная культура, религиоведческие дисииплины, преподавание в высшем учебном заведении

Введение в средней школе модуля «Основы религиозной культуры и светской этики» поставило перед педагогическим образованием задачу совершенствования подготовки учительских кадров с точки зрения освоения ими новых методик представления религиозной культуры в рамках учебного процесса. То, что эти методики во многом отличаются от традиционных подходов, связано с особенностями феномена религии.

Вопреки распространенному представлению о том, что в основе религии лежит «вероучение», т. е. структурированное изложение принципов той или иной религиозной веры, в реальности сами указанные принципы являются плодом опыта, составляющего практический фундамент любого религиозного учения. В отличие от линейных, разложимых на меньшие составляющие феноменов, подобных словесному тексту, религиозный опыт плохо поддается изучению средствами рационалистического познания.

Как показал У. Джеймс [1], общей чертой для всех религий является целостность и недискретность религиозного опыта, включающего в себя множество ощущений, переживаний, эмоций, а также то, что такой опыт во многих случаях не поддается вербализации. А. П. Забияко пишет, что «зачастую, согласно признаниям переживших религиозный опыт людей, подробное воссоздание его когнитивного содержания чрезвычайно затруднительно, поскольку полученное знание с трудом поддается (или вообще не поддается) словесному выражению - оно невербализуемо. В таких случаях средствами выражения... могут выступать графические символы (напр., мандала), звуки, изображения (напр., иконы), музыка, поведенческие акты (напр., смех) и иные способы передачи смыслов» [2, с. 866-867].

Специфика характера религии как формы познания мира диктует и особый подход к изложению религиоведческой информации в учебном процессе, когда преподавателю для адекватной передачи знаний о религии требуется использовать средства и методы, изоморфные неделимому на меньшие составляющие феномену религиозного опыта. Одним таких из средств передачи религиоведческих знаний является экскурсия в культовые соо- 
ружения различных конфессий, когда собственно словесный рассказ о религии сопровождается погружением в ее пространство (например, пространство храма), формируя целостную картину культуры.

Следует отметить, что в России, где экскурсионное дело начало развиваться с рубежа XIX-XX вв., практически отсутствует опыт проведения экскурсий на религиоведческую тематику. Классификация экскурсий, которую приводит журнал «Русский экскурсант» за 1916 г. (историко-археологические, историко-литературные, естественно-исторические, на фабрики и заводы, художественно-географические и этнографические, экскурсии трудовой помощи, общеобразовательные и бытовые, экскурсии отдыха и развлечений), вовсе не включает посещение культовых сооружений различных религиозных конфессий [3, с. 5056]. Это объясняется тем, что до 1917 г. подавляющее большинство населения страны имело определенную религиозную принадлежность, в связи с чем не было специальной необходимости в проведении экскурсий на такие темы. Иной стала ситуация, когда в течение советского периода произошла утрата базовых религиоведческих знаний, в связи с чем возникла проблема знакомства с религиозной традицией людей, не интегрированных в нее.

Так появляются экскурсии на религиоведческую тематику, в том числе в высших учебных заведениях. Специфичность такого способа презентации религиозной культуры отмечается в настоящее время рядом авторов, анализирующих роль и место экскурсии в культовые сооружения различных конфессий в духовно-нравственном воспитании студенчества [4], формировании и расширении кругозора обучающихся [5]. Подчеркивается важность и необходимость изучения религиозной культуры с точки зрения общепринятых мировых стандартов высшего образования [6]. В последние годы появляются работы, в которых затрагивается методика проведения экскурсии на религиоведческую тематику, хотя чаще всего она соотносится с методикой проведения обычной музейной экскурсии с минимальным анализом специфики именно религиоведческой экскурсии [7, с. 294-295; 8-10].

Однако ряд вопросов, имеющих конкретно-практическое значение, все еще слабо освещен в литературе. Среди них соотношение темы экскурсии и конфессиональной ориентации аудитории, особенности восприятия обучающимися полученных знаний и, конечно, общие методические принципы организации экскурсии в культовые сооружения различных конфессий, которые, очевидно, должны отличаться от экскурсий другого рода (исторических, искусствоведческих, краеведческих). Представляется, что накопленный к настоящему времени эмпирический материал уже позволяет обсуждать эти и многие другие аспекты религиоведческой экскурсии, пусть и в дискуссионном ключе. В данной статье авторы делают такую попытку на основании опыта, накопленного Томским государственным педагогическим университетом (ТГПУ) за последнее десятилетие.

Экскурсии в культовые сооружения различных конфессий начали проводиться в ТГПУ с 2009 г., когда дисциплина «Религиоведение» стала изучаться студентами специальности «Культурология». Кроме того, экскурсионная работа проводилась в рамках курса «Этноконфессиональное взаимодействие в истории Томска XVII-XX вв.» для студентов специальности «История» (с 2010 г.), а также музейной практики. В настоящее время данные мероприятия проводятся при изучении религиоведческих дисциплин для магистрантов профиля «Историческое образование» и студентов бакалавриата профиля «История и обществознание».

В качестве методической основы проведения экскурсии с самого начала был избран общепринятый в современной науке феноменологический подход к религии. Он предполагает рассмотрение религиозной культуры с точки зрения ее собственных логики, содержания и смысла, без попыток установить истинность или ложность того или иного религиоз- 
ного учения. Это, в свою очередь, исключает оценочные суждения любого характера в отношении религиозного мировоззрения, сосредоточивая внимание слушателей на получении конкретных знаний. Представляется, что тем самым практически снимается вопрос о том, насколько знакомство с религией в формате урока или экскурсии может оказать воздействие в направлении интеграции обучающихся в ту или иную конфессию - проблема, вызывающая в настоящее время беспокойство слушателей религиоведческих дисциплин как в высшем учебном заведении, так и в средней школе.

Примером того, как феноменологический подход не только дает слушателям возможность получения знаний о религии без интеграции в конфессию, но и снимает проблему мировоззренческой ориентации аудитории экскурсии, являются музейные практики ТГПУ, проводившиеся в 2009-2012 гг. В этот период группы студентов (15-20 человек) выезжали в г. Псков, город, тесно связанный с историей Древней Руси. Здесь до настоящего времени сохранились действующие храмы XI-XIII вв., находится Псково-Печерский монастырь (рисунок), единственный в России, где с XV в. не прерывалась иноческая жизнь. Таким образом, музейная практика проводилась в городе с достаточно плотной православной конфессиональной средой.

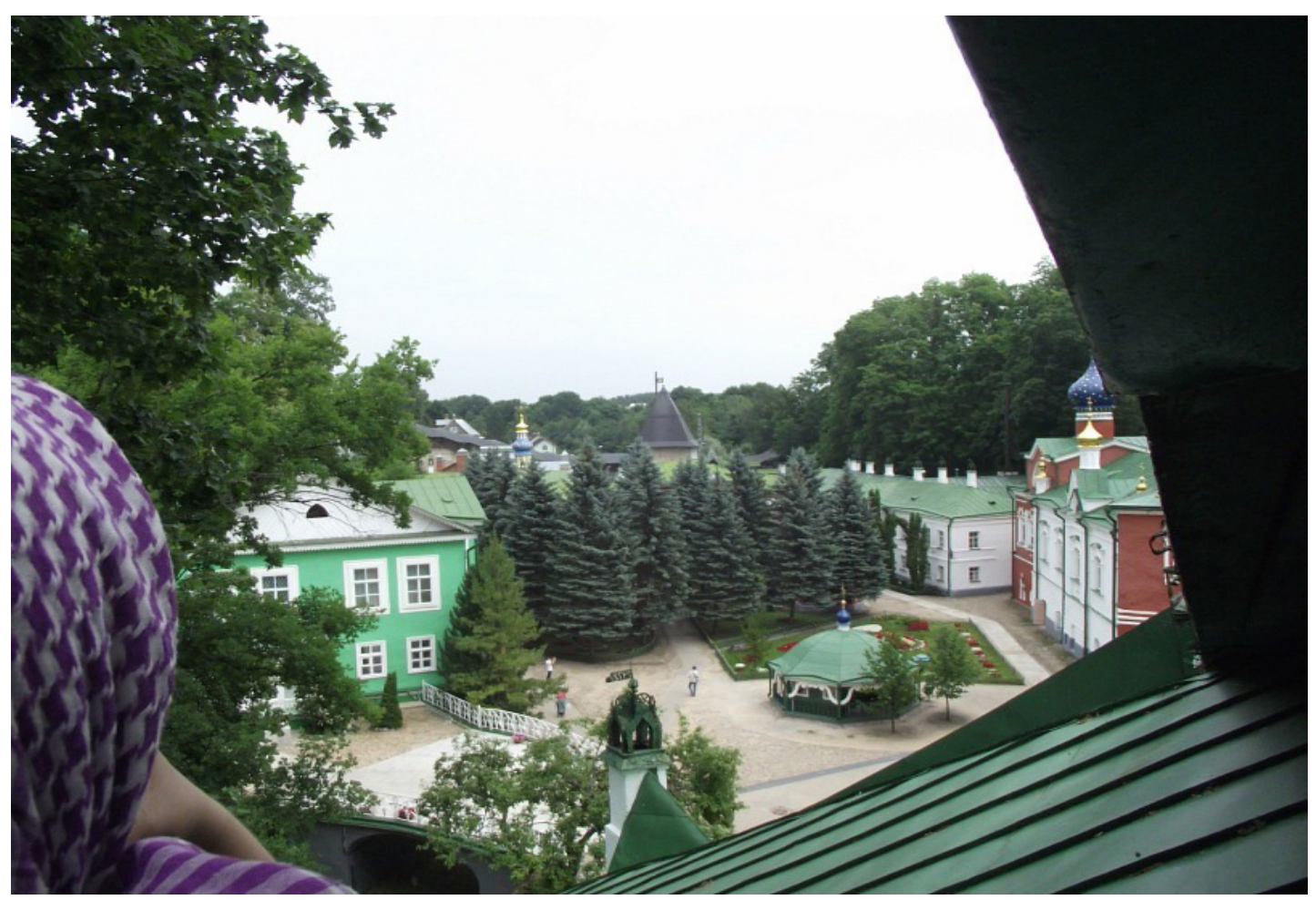

В Псково-Печерском монастыре. Фото студента ТГПУ Александра Юрченко

В связи с конфессиональной ориентированностью практикантов во многом особый случай представляла собой музейная практика 2011 г. Группа состояла из студентов специальностей «История», «Русский язык и литература», «Культурология». Не менее половины студентов изначально имели негативный опыт общения с православной конфессией, в связи с чем не были настроены на восприятие материала, связанного с христианством и его историей на Руси. Это могло создать серьезные трудности для преподавателей, руководящих практикой. Однако эти сложности оказались сняты через простое погружение в городское пространство Пскова, его историю, в которую органично вплетена и религия.

По приезде в Псков сразу началась экскурсия по городу, первым пунктом которой был Псковский Кремль. Кремль построен в IX-XII вв. и хранит не только память об истории 
города, но и представляет особенности его планировки, связанные с идеей Пскова как «дома Святой Троицы» и места Страшного Суда [11]. Большое впечатление произвели на практикантов развалины находившихся вокруг Кремля 24 церквей (снесены Петром I). 24 церковных престола соответствуют 24 старцам из Откровения Иоанна Богослова, которые будут совершать последний суд над человечеством. В этой же связи находится особая ориентация храмов Пскова и его окрестностей - на Кремль, а не на восток, согласно православной традиции. Особое внимание привлек Троицкий собор, сакральное сердце города. Так состоялось знакомство с мышлением и мировоззрением людей совершенно иной, отличной от современной, культуры. Имея тысячелетнюю историю, традицию, отразившуюся в архитектуре города, эта культура не могла не вызвать интереса и уважения, что и сняло проблему отношения к конфессии как таковую.

В дальнейшем, хотя в группе находились студенты различной конфессиональной ориентации (включая буддизм, ислам), это не помешало им с живейшим интересом воспринимать и глубоко анализировать материал экскурсий, а в качестве зачетной экскурсии (которую необходимо было подготовить по результатам практики и представить на итоговой конференции в Томске) большинство выбирали конфессиональные объекты (Троицкий собор, Псково-Печерский монастырь, храмы города). При этом по итогам поездки в группе не было ни одного случая смены личной конфессиональной принадлежности. Практика, однако, оказала влияние на мировоззренческие установки студентов в плане формирования уважения и глубокого интереса к другой конфессии и культуре. Именно это является основой формирования толерантности, терпимости к иным взглядам и культуре, но вместе с тем и уважительного интереса к иным культурным установкам, образу жизни.

Таким образом, можно сделать вывод о том, что феноменологический подход, с одной стороны, гарантирует достаточную степень духовной безопасности экскурсий на религиоведческую тематику (даже в случае плотной конфессиональной среды, которую можно видеть в г. Пскове), с другой - обеспечивает заинтересованность аудитории в получении знаний о религиозной культуре.

Вместе с тем представляется, что во время экскурсий оптимально погружение лишь в сакральное пространство конфессии, но не в ее религиозную практику, которая, кроме пространства, включает в себя множество других элементов (ритм богослужения, его язык, цветовое решение и др.), действительно способных оказать психологическое воздействие. Помимо того, что такое воздействие представляет собой неприемлемое вторжение в духовную жизнь человека, оно к тому же далеко не всегда приводит слушателя к конфессиональному выбору. Так, некоторые студенты, негативно настроенные в отношении религии, отмечают, что подобная позиция возникла еще в школьные годы, после посещения богослужения по инициативе преподавателя религиоведческой дисциплины. Участие неподготовленного человека в длительном и непонятном «действе» приводит не столько к стремлению глубже узнать религию, сколько к «травме» религиозной культурой, что сильно затрудняет дальнейшее ее изучение.

В силу этого, традиционные конфессии обычно не приглашают экскурсантов к участию в богослужении, тогда как религиозные общины, имеющие малое число последователей (в России к таковым можно отнести мормонов, баптистов, меннонитов и др.), как правило, стремятся совместить экскурсию в культовое сооружение с участием в ее практике. Позиция же традиционных конфессий вполне соотносится с феноменологическим подходом к религии, ориентированным на понимание религиозной культуры, а не на ее трансляцию или убеждение слушателей в истинности/ложности веры. Именно это обеспечивает восприимчивость аудитории к знаниям, которые отражают суть вероучения и мировоззренческих установок религии. 
Действенность выработанного подхода к проведению подобных экскурсий в дальнейшем подтвердилась в ходе аудиторной работы. Так, в рамках дисциплин «Религиоведение», «Этноконфессиональное взаимодействие в истории Томска XVII-XX вв.» студенты бакалавриата и магистратуры историко-филологического факультета ТГПУ в течение последних 10 лет посетили различные культовые сооружения г. Томска, например БогородицеАлексеевский монастырь, католический костел, иудейскую синагогу, мечети и лютеранскую кирху.

Полученный опыт позволяет более предметно говорить о тех знаниях и умениях, которые обучающиеся получают в ходе подобных мероприятий. Следует отметить, что результаты посещения экскурсий у студентов бакалавриата и магистратуры неодинаковы. Это связано со спецификой учебных дисциплин, на базе которых проводятся данные экскурсии, а также с особенностями ожиданий и запросов самих слушателей.

Так, студенты бакалавриата, посещающие различные культовые сооружения в рамках дисциплины «Религиоведение», в зависимости от исходных установок, обычно делятся на несколько категорий. Есть те, кто в силу научных интересов изучает определенную конфессию. Как правило, они заинтересованы в подобных экскурсиях, поскольку видят в них возможность ближе познакомиться с объектом своего исследования. Есть и студенты, проявляющие живой интерес к религии как части духовной культуры. На экскурсиях они надеются узнать что-то новое о конфессии. Наконец, среди обучающихся встречаются негативно настроенные по отношению к религиозной культуре, воспринимающие ее как нечто чуждое. Такие экскурсии они воспринимают настороженно, ожидая со стороны ее представителя навязчивой миссионерской деятельности, направленной на экскурсантов.

Однако после первой же экскурсии общий настрой группы изменяется. Если вначале студенты держатся настороженно в непривычной им обстановке, то после знакомства с конфессией посредством общения с ее представителем в сакральном пространстве, они начинают задавать вопросы, демонстрируя искренний интерес к религии, которой посвящена экскурсия. Побывав на нескольких экскурсиях, многие отмечают, что для них это редкая возможность пообщаться с представителями конфессий, поскольку самостоятельно они не решились бы на знакомство с этой культурой в подобном формате. Кроме того, обучающиеся, особенно те, кто был негативно настроен по отношению к религиозной культуре, приходят к выводу, что те реальные люди, с которыми они общаются в ходе экскурсий, отличаются от образа представителя конфессии, существующего в их сознании, в лучшую сторону, так как они не предпринимают попыток превратить пришедших на экскурсию студентов в последователей своей религии.

Таким образом, можно сделать вывод, что благодаря посещению подобных мероприятий, в ходе которых обучающиеся могут пообщаться с представителем конфессии в непринужденной обстановке и получить ответы на вопросы, которые порой проблематично найти в исследовательской литературе, со студентами происходит настоящая трансформация: религиозная культура больше не вызывает отторжения, просыпается живой интерес к религии как элементу духовной сферы жизни общества, а сами экскурсии начинают восприниматься как наиболее ожидаемые и продуктивные занятия по дисциплине «Религиоведение».

Магистранты, в свою очередь, посещают экскурсии в культовые сооружения различных конфессий в рамках дисциплины «Этноконфессиональное взаимодействие в истории Томска XVII-XX вв.». Среди них обычно присутствуют практикующие педагоги, которые заинтересованы в этой дисциплине и, как следствие, в экскурсиях, так как в их профессиональной деятельности возникают ситуации, когда необходимо организовывать подобные занятия для учеников. Поэтому учителя с удовольствием посещают экскурсии, обращая 
особое внимание на методическую организацию этих занятий, и получают опыт знакомства с религией как элементом духовной культуры на «живом» материале, предполагающем посещение сакрального пространства и общение с представителем конфессии. Этот опыт не сводим к поверхностному знакомству с конфессией или религиозной пропаганде.

В магистратуру также приходят студенты, решившие после получения степени бакалавра заняться научной деятельностью. Они с удовольствием посещают различные культовые сооружения, поскольку на этих занятиях им предоставляется возможность пополнить свои знания о традиционных конфессиях, используя местный материал, и познакомиться со спецификой этноконфессионального взаимодействия на территории Томска. Таким образом, в ходе таких экскурсий магистранты приобретают новые знания, позволяющие им лучше понимать процессы этноконфессионального взаимодействия на территории Томска, и учатся организовывать подобные экскурсии, что особенно важно для практикующих педагогов.

В целом живое знакомство с религиозной культурой, ее сакральным пространством, носителями конфессии позволяет студентам не только углубить и закрепить знания, полученные в ходе аудиторной работы, но и зачастую по-новому взглянуть на религиозную культуру в целом. Условиями эффективности религиоведческой экскурсии можно считать:

- отказ от оценочных суждений об истинности или ложности того или иного религиозного учения;

- акцент на истории и культуре, повседневной жизни религиозной конфессии;

- понимание ограничений, которые накладывает экскурсия такого рода, связанных с нежелательностью участия в религиозной практике.

При соблюдении этих условий экскурсия, обогащая знания студентов о религии, сохраняет в неприкосновенности личное пространство человека и не навязывает чуждые ему ценности. При этом оптимальным является посещение традиционных для России культовых сооружений, подход которых к работе с экскурсантами тождествен феноменологическому подходу к религии, обеспечивающему получение и закрепление знаний о конфессии. Дальнейшее развитие практики проведения экскурсий, безусловно, поставит и новые проблемы, среди которых - специфика подготовки экскурсии и формирования ее маршрута, особенности проведения религиоведческой экскурсии преподавателем и представителем конфессии, методика использования в экскурсиях медиаматериалов (виртуальная экскурсия в различные культовые сооружения) и многие другие, все еще ждущие анализа и решения.

\section{Список литературы}

1. Джеймс У. Многообразие религиозного опыта. М.: Наука, 1993. 432 с.

2. Забияко А. П. Религиозный опыт // Религиоведение: энциклопедический словарь. М.: Академический проект, 2006. С. 866-867.

3. Ярославское совещание по вопросу об экскурсиях // Русский экскурсант. 1916. № 3. С. 50-56.

4. Гавриленков А. Ф. О роли религиоведческих дисциплин в духовно-нравственном воспитании студенчества (на примере вузов Смоленщины) // Теория и практика современного образования: актуальные проблемы и перспективы развития: материалы всерос. науч.-практ. конф. Рославль, 2014. С. 40-45.

5. Герасимова А. П., Тысько Л. А. Знакомство студентов третьего курса историко-филологического факультета МарГУ с традиционной марийской религией во время музейной экскурсии // Актуальные исследования - 2018: сб. ст. по материалам междунар. науч.-практ. конф. / под общ. ред. А. И. Вострецова. М.: Мир науки, 2018. С. 26-31.

6. Окорочкова В. М., Старостина А. П. Духовно-нравственное воспитание студентов младших курсов Аэрокосмического университета // Вестник Самарского государственного аэрокосмического университета им. академика С. П. Королёва. 2009. № 3-1 (19). С. 313-317. 
7. Филиндаш Л. В. Конфессиональное многозвучие в социокультурном образовательном пространстве // Вестник университета. 2016. № 7-8. С. 290-295.

8. Паудяль Н. Ю., Филиндаш Л. В. Музейная коммуникация в современном социокультурном пространстве // Актуальные проблемы русского языка и культуры речи. Иваново, 2014. С. 44-56.

9. Ковалёнок Ю. Е. Потенциал музейной педагогики в духовно-нравственном воспитании (на примере этнографической экспозиции Забайкальского краевого краеведческого музея им. А. К. Кузнецова) // Укрепление единства российской нации и этнокультурное развитие народов Забайкалья: материалы междунар. науч.-практ. конф. Чита, 2019. С. 271-274.

10. Дидур Е. А. «Основы религиозных культур и светской этики»: региональный опыт // Народное образование. 2011. № 8 (1411). С. 174-180.

11. Шулакова Т. В. «Вольный Стольный Господин Псков» - «Дом Святой Троицы» // Псковский регионологический журнал. 2006. № 2. С. 110-114.

Сазонова Наталия Ивановна, доктор философских наук, доцент, заведующая кафедрой истории России и методики обучения истории и обществознанию, Томский государственный педагогический университет (ул. Киевская, 60, Томск, Россия, 634061). E-mail: nataly-sib@mail.ru

Райкова Ольга Анатольевна, кандидат философских наук, доцент, Томский государственный педагогический университет (ул. Киевская, 60, Томск, Россия, 634061). E-mail: didenko.oa@list.ru

Материал поступил в редакичю 24.12.2019.

DOI 10.23951/2307-6127-2020-2-52-59

\title{
EXCURSIONS IN TEACHING RELIGIOUS STUDIES: EXPERIENCE OF TOMSK STATE PEDAGOGICAL UNIVERSITY
}

\author{
N. I. Sazonova, O. A. Raykova
}

\section{Tomsk State Pedagogical University, Tomsk, Russian Federation}

The article analyzes the experience of Tomsk State Pedagogical University in conducting excursions about religious culture. The necessity of excursions to denominations within religious disciplines is substantiated, the experience of presenting religions through excursions to confessions is presented. The article presents the experience of presentation of religions through excursions to confessions, obtained during the visiting Museum practice and during the classroom work of students of Tomsk State Pedagogical University (specialties "Cultural Studies", "History", bachelor's and master's degree "Pedagogical education"). The article deals with the specifics of the students of the excursion, the peculiarities of the reaction to religious culture, the nature of the knowledge gained, their influence on the formation of a professional teacher. On the basis of the experience of conducting excursions, the changes in the perception of religious culture that occur in the listeners are analyzed. It is stated that after excursions religious culture does not cause rejection, interest is shown in religion as an element of the spiritual sphere of society. Of particular importance is the tour for undergraduates who are teachers. In the course of visiting excursions, undergraduates acquire new knowledge that allows them to better understand the processes of ethnoconfessional interaction in the city of Tomsk, and learn to organize such excursions, which is especially important for practicing teachers. The ideological influence of religious excursions does not lead to the integration of the student into the denomination. Such integration is impossible without becoming involved in religious practice. This means that the excursion, giving knowledge about religion, keeps intact the personal space of a student and does not impose alien values. 
Keywords: excursion, religion, phenomenological approach, religious confession, religious culture, religious studies, teaching in higher educational institution.

\section{References}

1. Dzheyms U. Mnogoobraziye religioznogo opyta [Variety of religious experience]. Moscow, Nauka Publ., 1993. 432 p. (in Russian).

2. Zabiyako A. P. Religioznyy opyt [Religious experience]. Religiovedeniye. Entsiklopedicheskiy slovar' [Religious studies: an Encyclopedic dictionary]. Moscow, Akademicheskiy proyekt Publ., 2006. Pp. 866-867 (in Russian)

3. Yaroslavskoye soveshchaniye po voprosu ob ekskursiyakh [Yaroslavl session on the issue of the excursion]. Russkiy ekskursant, 1916, no. 3, pp. 50-56 (in Russian).

4. Gavrilenkov A. F. O roli religiovedcheskikh distsiplin v dukhovno-nravstvennom vospitanii studenchestva na primere vuzov Smolenshchiny [On the role of religious disciplines in the spiritual and moral education of students (on the example of universities of Smolensk region)]. Teoriya i praktika sovremennogo obrazovaniya: aktual'nye problemy i perspektivy razvitiya: Materialy vserossiyskoy nauchno-prakticheskoy konferentsii [Theory and practice of modern education: actual problems and prospects of development. Materials of the Russian national scientific and practical conference]. Roslavl, 2014. Pp. 40-45 (in Russian).

5. Gerasimova A. P., Tysko L. A. Znakomstvo studentov tretego kursa istoriko filologicheskogo fakul'teta MarGU s traditsionnoy mariyskoy religiyey vo vremya muzeynoy ekskursii [Acquaintance of the third year students of the faculty of history and Philology of MarSU with the traditional Mari religion during the Museum tour]. Aktual'nye issledovaniya 2018 Sbornik statey po materialam Mezhdunarodnykh nauchno-prakticheskikh konferentsiy. Pod obshchey redaktsiey A. I. Vostretsova [Actual research-2018. Collection of articles on the materials of International scientific and practical conferences. Under the General editorship of A. I. Vostretsov]. Moscow, Mir nauki Publ., 2018. Pp. 26-31 (in Russian).

6. Okorochkova V. M., Starostina A. P. Dukhovno nravstvennoye vospitaniye studentov mladshikh kursov Aerokosmicheskogo universiteta [Spiritual and moral education of students of junior courses of Aerospace University]. Vestnik Samarskogo gosudarstvennogo aerokosmicheskogo universiteta im. Akademika S. P. Koroleva-VESTNIK of Samara University. Aerospace and Mechanical Engineering, 2009, no. 3-1 (19), pp. 313-317 (in Russian).

7. Filindash L. V. Konfessional'noye mnogozvuchiye v sotsiokul'turnom obrazovatel'nom prostranstve [Confessional polyphony in the socio-cultural educational space]. Vestnik universiteta, 2016, no. 7-8, pp. 290-295 (in Russian).

8. Paudyal N. Yu, Filindash L. V. Muzeynaya kommunikatsiya v sovremennom sotsiokul'turnom prostranstve [Museum communication in the modern socio-cultural space]. Aktual'nye problemy russkogo yazyka i kul'tury rechi [Current problems of the Russian language and speech culture]. Ivanovo, 2014. Pp. 44-56 (in Russian).

9. Kovalyonok Yu. Ye. Potentsial muzeynoy pedagogiki v dukhovno-nravstvennom vospitanii na primere etnograficheskoy ekspozitsii Zabaykal'skogo krayevogo krayevedcheskogo muzeya imeni A. K. Kuznetsova [The potential of Museum pedagogy in spiritual and moral education (on the example of the ethnographic exposition of the Transbaikalian regional Museum of local lore named after A. K. Kuznetsov)]. Ukrepleniye edinstva rossiyskoy natsii i etnokul'turnoye razvitiye narodov Zabaykal'ya: materialy mezhdunarodnoy nauchno-prakticheskoy konferentsii [Strengthening the unity of the Russian nation and ethnocultural development of the peoples of Transbaikal: materials of the International scientific and practical conference]. Chita, 2019. Pp. 271-274 (in Russian).

10. Didur E. A. "Osnovy religioznykh kul'tur i svetskoy etiki" regional'nyy opyt ["Fundamentals of religious cultures and secular ethics": regional experience]. Narodnoye obrazovaniye, 2011, no. 8 (1411), pp. 174-180 (in Russian).

11. Shulakova T. V. "Vol'nyy Stol'nyy Gospodin Pskov" - "Dom Svyatoy Troitsy" ["Free city Pskov" - "House of the Holy Trinity"]. Pskovskiy regionologicheskiy zhurnal, 2006, no. 2, pp. 110-114 (in Russian).

Sazonova N. I., Tomsk State Pedagogical University (ul. Kiyevskaya, 60, Tomsk, Russian Federation, 634061). E-mail: nataly-sib@mail.ru

Raykova O. A., Tomsk State Pedagogical University (ul. Kiyevskaya, 60, Tomsk, Russian Federation, 634061). E-mail: didenko.oa@list.ru 